Revue

Revue de l'histoire des religions

de Ihistoire des religions

3 | 2017

Varia

\title{
Alessandra FERRARO, Una voce attraverso il velo.
} L'alterità del linguaggio mistico e missionario di Marie de l'Incarnation

Venise, La Toletta edizioni (« Secreta »), 2014

Alberto Frigo

\section{(2) OpenEdition}

Journals

Édition électronique

URL : http://journals.openedition.org/rhr/8803

DOI : $10.4000 /$ rhr.8803

ISSN : 2105-2573

Éditeur

Armand Colin

Édition imprimée

Date de publication : 1 septembre 2017

Pagination : 568-569

ISBN : 978-2-200-93127-8

ISSN : 0035-1423

Référence électronique

Alberto Frigo, « Alessandra Ferraro, Una voce attraverso il velo. L'alterità del linguaggio mistico e missionario di Marie de l'Incarnation", Revue de I'histoire des religions [En ligne], 3 | 2017, mis en ligne le 01 septembre 2017, consulté le 07 janvier 2021. URL : http://journals.openedition.org/rhr/8803 ; DOI : https://doi.org/10.4000/rhr.8803

Ce document a été généré automatiquement le 7 janvier 2021.

Tous droits réservés 


\section{Alessandra FERRARO, Una voce attraverso il velo. L'alterità del linguaggio mistico e missionario di Marie de l'Incarnation}

Venise, La Toletta edizioni (« Secreta »), 2014

Alberto Frigo

\section{RÉFÉRENCE}

Alessandra FERRARO, Una voce attraverso il velo. L'alterità del linguaggio mistico e missionario di Marie de l'Incarnation, Venise, La Toletta edizioni (« Secreta »), 2014, 126 p., $21 \mathrm{~cm}$, $15 €$, ISBN 978-88-97928-67-6.

1 La figure de Marie de l'Incarnation, mystique et missionnaire, a fait l'objet d'un nombre remarquable d'analyses de la part des historiens de la spiritualité et des anthropologues des religions au cours du dernier demi-siècle. Bourgeoise de Tours, entrée au couvent des Ursulines en 1631 après avoir abandonné son fils et futur bénédictin Claude Martin, Marie de l'Incarnation s'embarque pour la Nouvelle France en 1639. Elle fonde à Québec le premier couvent destiné à l'éducation et à l'évangélisation de jeunes Amérindiennes et joue dès lors un rôle capital dans la naissance de la colonie française. Longtemps dominé par les pages que lui consacra Henri Bremond et par les écrits hagiographiques des historiens québécois qui visaient à en faire une des protagonistes du «mythe fondateur» du pays (p.17), le débat sur l'ursuline a été renouvelé par l'édition critique de ses écrits (1929-1943) et de sa riche correspondance (1971). Plus récemment, l'essor des études postcoloniales et le renouveau d'intérêt pour les cultures amérindiennes, promu au Québec par la Révolution tranquille des années 1970, ont poussé les chercheurs à démasquer les 
implicites et les composantes idéologiques du témoignage fourni par Marie de l'Incarnation au sujet de son action missionnaire.

En se situant en aval de ce renouveau des études consacrées à celle que Bossuet appela «la Thérèse de nos jours et du Nouveau Monde ", Alessandra Ferraro en souligne les limites et esquisse une approche nouvelle. L'intérêt accordé aux écrits de Marie de l'Incarnation en tant que témoignage, souvent biaisé, d'une rencontre entre cultures différentes, risque en effet de passer sous silence sa valeur et sa spécificité littéraire. L'auteur souligne au contraire les multiples enjeux de l'écriture de Marie de l'Incarnation en l'interrogeant au fil de la triple rencontre avec l'altérité qui marqua l'existence de l'ursuline. Altérité anthropologique, d'abord, celle des « sauvagesses » de la Nouvelle France que la missionnaire voulait «franciser». Une analyse serrée de la correspondance de Marie permet de distinguer différentes stratégies de narration adoptées en fonction de différents destinataires. Dès lors, si les missives aux notables se rapprochent des relations de jésuites par leur caractère apologétique et par les "philtres idéologiques» souvent imposés aux données factuelles, les lettres privées témoignent au contraire d'un regard presque d'ethnographe, qui cherche à comprendre les coutumes et les comportements concrets des jeunes pensionnaires amérindiennes. Et cela sans minimiser les méprises ou les échecs des efforts accomplis pour créer un espace commun entre deux systèmes culturels qui se révèlent finalement inconciliables.

3 La découverte de l'altérité anthropologique se double toutefois chez Marie de l'Incarnation de la rencontre avec l'Autre mystique dont témoignent ses écrits spirituels. En prolongeant les analyses de Nathalie Zemon Davis, Nicholas Paige et Michel de Certeau, Alessandra Ferraro souligne que la « désacralisation de l'espace intérieur » qui rend possible l'avènement de l'autobiographie comme genre littéraire trouve sa source paradoxale dans le travail de mise en écriture de l'expérience mystique. À ce titre, les efforts de normalisation et « cannibalisation » (p. 91) des textes et des choix stylistiques de l'ursuline opérés par ses éditeurs jésuites et par son fils, qui en publient les "papiers ", témoignent en creux du caractère déroutant de son écriture, animée par une " parole abondante et "indistincte" » (De Certeau).

Missionnaire, mystique, mais, avant tout, femme, et c'est là une troisième forme d'altérité à laquelle se confronta Marie de l'Incarnation et dont A. Ferraro analyse avec originalité les enjeux. Car force est de constater que maintes pages de la Relation que l'ursuline rédige en 1654 à propos de son expérience missionnaire trahissent une volonté de sublimer « l'abandonnement » du fils : l'amour maternel, auquel Marie avait renoncé en entrant dans le couvent, se reverse désormais sur l'humanité " enfantine » de jeunes Amérindiennes. Mais la Relation s'adressant directement à Claude Martin, il y va finalement d'une étrange " confession spirituelle devant un fils inquisiteur ", qui est en même temps une apologie, un récit, et l'esquisse d'un chemin de perfection. En s'appuyant sur une longue fréquentation des sources et une lecture attentive des textes, cette étude esquisse un portrait remarquablement nuancé des multiples aspects de l'expérience humaine et intellectuelle de Marie de l'Incarnation. 


\section{AUTEURS}

\section{ALBERTO FRIGO}

Laboratoire d'études sur les Monothéismes. 